\title{
Effect of sub-critical water hydrolysis on sugar recovery from bakery leftovers
}

\begin{abstract}
Croissant and doughnuts are among the bakery products that are discarded daily. The main constituent of these leftovers is the starch that originates from the main ingredient, wheat flour. The aim of this study is to evaluate the effect of sub-critical water treatment on starch hydrolysis for the recovery of sugar. Experiments were conducted using a batch-type sub-critical water reactor at temperatures ranging from 100 to $374{ }^{\circ} \mathrm{C}$ for $1-$ 30 min with a solid loading of $10-90 \% \mathrm{w} / \mathrm{v}$. The sugar obtained from both samples increased with an increase in temperature between 100 and $200{ }^{\circ} \mathrm{C}$ after $1-10 \mathrm{~min}$ treatment time. Further increasing the temperature $\left(220-374^{\circ} \mathrm{C}\right)$ and time $(15-30 \mathrm{~min})$ resulted in a decrease in the total sugar yield, indicating that the sugars were degraded into other products. Contrary, increasing the solid loading $(10-75 \% \mathrm{w} / \mathrm{v})$ decreased the total sugar yield ( $421.58 \pm 0.95$ to $21.26 \pm 0.08 \mathrm{mg} / \mathrm{g}$ substrate for croissants and 409.26 \pm 0.95 to $13.21 \pm 0.06 \mathrm{mg} / \mathrm{g}$ substrate for doughnuts). The process conditions at 200 ${ }^{\circ} \mathrm{C}, 10 \mathrm{~min}$, and $10 \% \mathrm{w} / \mathrm{v}$ solid loading, yielded the highest total carbohydrate contents for leftover croissant and doughnuts, $421.58 \pm 0.95$ and $409.26 \pm 0.95 \mathrm{mg} / \mathrm{g}$ substrate, respectively. The starch was hydrolysed, forming fructose and glucose, and the amount of fructose was higher than that of glucose in all samples. The highest fructose and glucose were obtained from the leftover croissants: $4.74 \pm 0.12$ and $3.76 \pm 0.41 \mathrm{mg} / \mathrm{g}$ substrate, respectively. This study shows that sub-critical water treatment can be used as a green technology to recover sugar from bakery leftovers.
\end{abstract}

Keyword: Bakery leftovers; Croissants; Doughnuts; Sub-critical water treatment; Sugar; Fructose; Glucose 
